\title{
Insight
}

\section{Innovation and Metastability: a Systems Model}

\author{
$\underline{\text { Nick Winder }}^{1}$
}

\begin{abstract}
The culture trap is the tendency to put cultural markers and habits above the demands of reason or compassion. It can reduce receptivity to new ideas and trigger Phoenix Cycles of catastrophe and renaissance. System research is then complicated by the historiographic problem of continuity and change, because there are no objective criteria for deciding whether "the system" survived or was destroyed by the catastrophe. This paper explores the differences between uncertainty emergence and self-organizing emergence using the concept of a "possibility space" to clarify the relationship between anti-causal events and causal states, i.e., the meso-history of conjuncture. Conjunctures are interpreted ex post in the context of deep time. The paper distinguishes autopoiesis, i.e., a new instance of a species, from elaboration, i.e., the origin of new species. It also describes a spectrum ranging from metastability, in which the possibility space is time invariant, to innovation, in which the possibility space is a synergetic artefact of changing habits and beliefs. Metastable systems are computably complex; we can make predictions across the boundaries of successive conjunctures, subject to statistical uncertainties. Innovative systems are uncomputably complex; although we can make predictions within a conjuncture and anticipate bottlenecks, we cannot predict beyond the conjuncture because conceptual taxonomies will not be conserved. The relationship between adaptive potential and constraint remains fundamental, although debates about whether the system is resilient are meaningless. System boundaries are artefacts of a dynamic consensus. The analytical sciences use methods designed for metastable systems, whereas the discursive sciences presume innovation. These methods predispose researchers to different space-time perspectives that, in turn, make it possible to generalize about their roles in different policy arenas. Tensions between analytical and discursive scientists become more understandable and manageable if these historiographic issues are clarified. The relationship between innovation and metastability is illustrated in an appendix on the emergence of social complexity in Europe.
\end{abstract}

Key Words: adaptive potential; cultural ecodynamics; complex adaptive systems; innovation; metastability; resilience.

\section{THE PHOENIX CYCLE}

In the history of the Earth, co-evolutionary catastrophes, in which one population undermines the fitness of another (Norgaard 2005, Winder et al. 2005), seem to have alternated with periods of complexification and rapid social change. Some of these catastrophes were interspecific, such as epidemic disease, in which parasites change mortality and survivorship in the host population. Others were intraspecific, e.g., competition for limited resources between populations of the same species. Some were symmetrical: Warfare is a case in point. Others were asymmetrical, e.g., slavery, subjugation, and inequitable trade.
The first half of the 20th century brought coevolutionary catastrophes on such unprecedented scales that a new word, "genocide," was coined to describe them. Complex system theory, the intellectual framework of this paper, came into being at the end of World War I and was consolidated in the aftermath of World War II. The roaring $20 \mathrm{~s}$ and the swinging $60 \mathrm{~s}$ had many parallels, including a widespread rejection of conventional morality, a growing concern about environmental degradation, rapid technological change, and an interest in the science of complexity. The complexity revolutions and genocide of the 20th century are part of the same Phoenix Cycles. 
Bertrand Russell (1961) wrote of a negative correlation between stability and creativity that helps to explain these cycles: "A stable social system is necessary, but every stable social system hitherto devised has hampered the development of exceptional artistic or intellectual merit. How much murder and anarchy are we prepared to endure for the sake of great achievements such as those of the Renaissance? In the past, a great deal; in our own time, much less. No solution of this problem has yet been found, although increase of social organization is making it continually more important."

Russell was already an old man in the 1960s, but his sentiments captured the spirit of the times. The chaos of early modern Europe with its dying theocracies and emerging technocratic systems had many resonances in the developing world. Remedial aid, unless it raised the expectations of the poorest people, simply fueled population growth, aggravating environmental degradation in the present and increasing future needs. This Malthusian ratchet was wholly pernicious (Bhagwati 1966), but our only strategy for disengaging it seemed to be to increase the world's productivity, driving economic growth and social stratification.

It was already clear that economic growth could not be sustained indefinitely, but established technocracies were locked into social engineering, inequitable trading patterns, and the Cold War arms race and so found it hard to change direction. Schumpeter's (1939) work on the relationship between research and innovation was cited to justify a command economy for research services, but his observation that an innovation was not the same as an invention was largely ignored. By the 1970s, many environmentalists suspected that nothing short of a global catastrophe, i.e., the Doomsday Scenario, would weaken social constraints enough to permit a less technocratic approach.

The slow-motion catastrophe of Cold War policies polarized trade relations, causing many millions more to die of avoidable diseases, desertification, violent oppression, and poverty. Communist revolutions in the Far East added to the sense of pessimism, and the responses of the superpowers hardly inspired confidence. The Doomsday Scenario would certainly have effected substantial change, but long-term trends suggested hideous collateral damage. It was possible that such a catastrophe would trigger a global extinction cascade comparable to the one that occurred at the Cretaceous-Tertiary interface.

Ernst Schumacher (1973) made a substantial contribution by highlighting problems of subsidiarity. Like many others of his generation, he argued that we were consuming the world's capital as though it were disposable income. The practice of economics "as if people mattered" demanded actions tailored to accidents of history and geography and the use of appropriate technology. According to Schumacher (1973:31): "The greatest danger invariably arises from the ruthless application, on a vast scale, of partial knowledge." He and others writing in a similar vein were particularly concerned about social engineering and technocratic extremism. These concerns were played down by governments and ridiculed by many scientists, actions that later polarized the postmodern debate.

Mainstream science departments still provided niches for holistic thinkers, and the post-war systems revolution was still committed to integrating humanistic and scientific perspectives. Upgrade and downgrade cycles were known to be common. We find them in botany (Watt 1947), in the cycling of predators and prey (Volterra 1926), and in the complex hide-and-seek behavior of experimental microcosms (Huffaker 1958).

Holling (1973) characterized a general adaptive cycle and argued that human action to maximize the sustainable yield of an ecosystem gave it a certain brittleness or rigidity that made catastrophic disintegration likely. The concept of system resilience as a balance between constraint or connectedness and adaptive potential suggested links between the Phoenix Cycle of catastrophe and renaissance, the problems exercising environmentalists and complex systems research.

Beginning in the 1960s, a number of authors, notable among them Richard Buckminster-Fuller and Kenneth Boulding, likened the Earth to a spaceship whose life-support systems depended on effective recycling and purification. The possibility that carbon emissions, refrigerants, and aerosol propellants would damage the ozone layer began to engage environmentalists in the 1970s but was strongly resisted by governments and multinationals. By the end of that decade, James Lovelock (1979) had offended many of his peers by suggesting that global life-support systems were comparable to a 
biological organism, i.e., a complex adaptive system able to maintain its internal parameters in the face of environmental and metabolic fluctuations.

Lovelock's theory was a natural extension of von Bertalanffy's (1968) thesis that ecosystems and institutions are organisms. In turn, von Bertalanffy was building on foundations laid by Herbert Spencer in the 19th century. However, many scientists were dismayed by the suggestion that the Gaia system could have properties that were not deducible from those of its constituent subsystems. Atheism and reductionism had become cultural markers in science, and the idea that the whole was more than the sum of its parts seemed metaphysical.

Public concern about sustainable development (Brundtland 1987), global warming, the management of the water cycle, and the disaster at Chernobyl created a growing awareness of global and transnational commons through the $1980 \mathrm{~s}$. By the time the Maastricht treaty was signed, subsidiarity had ceased to be the concern of theologians and environmentalists and become a high-profile political issue. Policy makers began to accept that, although small is often beautiful, large is sometimes necessary. We cannot mount an effective response to global warming at the level of the village council. Each system is bounded to respect different spatiotemporal scales, and the people managing them explore different possibility spaces.

Systems practitioners have responded by developing integrative, multiscalar approaches to complexity. System theory has become the search for the analytical scales (Boulding 1956, Gell-Mann 1994), the spatiotemporal scales (Hägerstrand 1987, Gunderson and Holling 2001), and the cultural scales (van der Leeuw 1998) on which systems emerge and tractable problems can be posed. However, neither system theory nor any other intellectual agenda has objective criteria for distinguishing good from bad systemic reorganization. Few people would grieve if the anopheles mosquito was annihilated, but the loss of a species of butterfly causes consternation. Viewed dispassionately, they are catastrophes of the same logical type, but we do not view them this way.

Further progress will not be made by annotating pictures of the Phoenix Cycle, because the cycle itself challenges the very ontology of the systems method. Whereas von Bertalanffy felt able to assert that there were systems everywhere, we now understand that this is not true. Abstract systems are at least partly the products of the embodied mind, instantiated again and again in different problem domains (Read 2003; see also Poincaré 1952, Lakof and Núñez 2000). To know whether a system has persisted or been destroyed, we first need to know what the system is. That is a taxonomic problem.

Scientists of the later 20th century often avoided discussing these boundary judgments because they led to semantic arguments that hampered research. In the analytical sciences, boundary judgments are often made expediently for the sake of argument. We locate the scales on which a robust, quasiclassical system comes into focus. Once those judgments are made, fiddling around with boundary judgments is inimical to analytical method. We therefore take the boundary of the system as given and time invariant, even though we know very well that it is an emergent phenomenon. This creates a correlation between boundary judgments and operational judgments, i.e., methods and problemsolving strategies.

Discursive scientists, on the other hand, understand that the boundary judgments that define systems and problem domains coincidentally determine who or what is a stakeholder and who or what is beyond the pale (Vickers 1965, Boulding 1978, Churchman 1979). For this reason they may try to negotiate new system boundaries that maximize social inclusion (Flood and Jackson 1991, Rosenhead and Mingers 2001). Environmental activists also advocate new boundary judgments to emancipate nonhuman species and minorities (Carson 1962, Naess 1989, Lee 1993). In this they may find themselves opposed by an alliance of politicians and analytical scientists whose professional credibility rests on the proposition that complex socio-natural systems are safer in their hands.

\section{A NATURAL SUBSIDIARITY}

All sciences presuppose a working taxonomy, i.e., an ontology of categories and methods used by practitioners. The analytical sciences need taxonomies that are robust over very large intervals of space and time. The ontology of atoms and chemical bonds, electrons, masses, and positions, for example, can be applied to physical systems over huge intervals of space and time. This stability lends itself to predictive methods. We can predict the behavior of massive objects or chemical reactions 
and test these predictions experimentally. Although philosophers argue that goodness of fit proves nothing (Popper 1959), the dependability of physical laws is the mainstay of applied science.

The applied analytical sciences need dependability, and this encourages us to look for systems under such extreme constraint that their behavior can be predicted. By applying analytical methods to these simple systems, we can develop technical infrastructure that facilitates certain types of actions, such as the Internet, roads, institutions, factories, and so on. The products of applied science usually become manifest as "pockets of local order" (POLOs) in the landscape (Hägerstrand 1975, 1985). Human behavior is influenced by these POLOs, which underpin cooperative responses to threats or opportunities.

This emphasis on collective action and technical infrastructure creates a natural link between the analytical sciences and large institutions such as multinational companies, national and supranational polities, etc. These are the agencies with the power to respond or to block responses to the demands of global and transnational commons like the oceans, great river catchments, forests, and the atmosphere. In general, large institutions are slow moving. Their survival depends on maintaining the status quo. They are heavily sectorialized and constitutionally incapable of responding to accidents of local history and geography.

Discursive scientists, however, understand that it is not the POLOs that make individual lives meaningful, but the habits and rituals that help us maintain contact with valued resources, including other people. To treat these structured activities as a goal-directed sequence of processes is like pretending that lovers eat together because food is cheaper purchased in bulk and you only need one kitchen.

Having identified unacknowledged stakeholders in the present, discursive scientists are more interested in emancipating them than in manipulating the landscape to produce new POLOs. This diverts attention from constraints, infrastructure, and stability to structured activities and political and social change. Sociological "laws" are so localized in space and time that the use of the word is almost absurd. Those social systems whose behavior is predictable are usually so severely constrained that there are many unacknowledged stakeholders to be found. Consequently, large institutions often find the very presence of discursive scientists irksome.

Large institutions may use their financial and political muscle to shift resources from discursive science, and disruptive local issues, to analytical science and the status quo. When these "incentives" are perceived as inequitable, as they have been over the past two decades, the methods of analytical and discursive science become cultural markers. The political power struggle between large and small institutions may be played out in gladiatorial combat between analytical and discursive scientists. Humanists interested in perceptual change are accused of believing that material objects did not exist until people knew about them. Engineers, with a culturally embedded commitment to universal time and invariant taxonomies, are linked to political hegemony and accused of answering the questions they wished someone had asked them. This is the issue at the heart of the post-modern debate.

Often the real losers in this power struggle are stakeholders operating at the regional level. Regions occupy an intermediate position between the extremes of universality and particularism. The success of large-scale policy initiatives is critically dependent on processes at these intermediate levels (Folke 2003, Urry 2003). Regional policy makers work across sectors. They have to deal with national and supranational institutions and balance their demands against the conflicts of interest engendered among local and regional communities.

The most demanding integrative research projects are invariably mounted at the regional level, where discursive and analytical scientists come together to work between scales (Winder 2004, 2005, 2006), and have to deal with complex linkages among boundary judgments, value judgments, and operational judgments that make it impossible to disentangle culture from nature and science from politics.

The systems characterized in these integrative problem domains certainly do not form a conventional ecological hierarchy (Koestler 1967, Allen and Starr 1987) or even a panarchy, defined by Holling (2001:31) as a "representation of a hierarchy as a nested set of adaptive cycles." Integrative systems become manifest on a range of 
scales, not just spatial and temporal but also analytical and cultural, and do not fit any overarching hierarchical schema.

Indeed, socio-natural systems can be so poorly structured that a well-meaning intervention in one arena can have unforeseen and undesirable spin-off effects in another. The shift from institutionalized slavery to international trade, for example, seems like a resilient transformation viewed from the point of view of an advanced technocracy, but, for a starving child in the Third World or another sold into prostitution to service the tourist trade, the evidence of progress is less clear.

Supranational agencies and multinationals can paralyze integrative research simply by raising the stakes. Despite investment in inclusive governance, the impact of all this consultation and investment on policy is often negligible. Regional stakeholders become disenchanted because there is no route to emancipation that does not involve a catastrophic system collapse. Research managers need to be aware of this ethical dilemma. Without buy-in from larger institutions, governance and integrative research teams can actually aggravate social exclusion by destabilizing the socio-natural systems that they are created to serve.

\section{STRUCTURE AND CULTURE}

In a world in which one species has entrained global life-support systems, it may be useful to know what makes individuals of that species happy. Humans, for example, are obligate social animals, as unable to thrive alone as ants or bees. Natural selection has shaped our predisposition to familiar, almost liturgical activity. We play games, participate in organized religious or secular rituals, make music, watch soap operas, or walk in the garden.

Structure is an abstract organizing tendency instantiated in many activity sets. It is not the behavior itself, but the patterns, habits, and mannerisms coded into that behavior that give us a sense of familiarity. Language, for example, is highly structured. It constrains vocabulary and syntax, of course, but that discipline facilitates communication. It also appeals to an aesthetic sense that allows us to distinguish insiders from outsiders in terms of structural nuances.
We can see the precursors of structure in nonhuman species. The regional dialects of songbirds are a case in point. Some of the co-evolutionary rapprochements we find in predator-prey relations may also be the products of social structure. So-called "prudent" predators (Slobodkin 1961) that focus on older and weaker prey are capable of learning and imitating. Wolves, for example, are very receptive to structural nuances and assimilate well into human societies. Dogs were probably our earliest domesticate.

Humans are born unable to communicate, but expecting to encounter communicators. This hardwired expectation that the material world will want to communicate with us is implicate in symbolic and representational art, literature, theology, and science. As children, we are driven to achieve congruence; as young adults, to experiment; and, as elders, to simplify and teach. If our beliefs were not a little conservative later in life, structures would change so fast that communication would become impossible. When structures become fixed in this way, anthropologists often speak of culture.

Culture determines the actions we do not take and the options we do not consider. It is a tacit behavioral constraint that enables us to respond unconsciously, by reflex, to a familiar situation. It coincidentally makes us unreceptive to alternative ways of thinking or acting. Culture and the structured behaviors it fixes may also represent communal identity, as a badge might mark membership in a fraternity. People who violate cultural norms often find themselves coerced, excluded, or even attacked by their neighbors.

The cultural imperative has made us imitative, coercive, communicative, mystical, moral creatures. It has also laid a deadly trap for us. In times of conflict, structured behaviors become cultural markers that we use to justify ignoring the demands of reason or compassion. The problem is not that the prohibited actions are inherently repugnant, but that normative violations are disruptive. Cultural markers determine who has the right to the protection of the community and who stands beyond the pale. A violation that would otherwise scarcely be noticed may now trigger furious reprisals. People begin to argue about tacit knowledge, semantics, and morality.

The emancipation of slaves, the abolition of public executions and of blood sports like bear-baiting and 
cockfighting, legislation to protect natural resources or health and safety in the work place, and controls on the advertising and distribution of harmful recreational drugs like alcohol and tobacco all hinged on conceptual adjustments that changed our collective understanding of who or what must be considered a legitimate stakeholder. Each of these reforms was opposed on the grounds that the new ontology flew in the face of common sense, denied the natural order, and violated cultural markers.

The culture trap is a byproduct of our sociability, adaptive potential, and need for familiar structured behavior. It exists because we are what we are. As Vickers (1972) explains: "A trap is only a trap for creatures which cannot solve the problems that it sets. Mantraps are dangerous only in relation to the limitations on what men can see and value and do. The nature of the trap is a function of the nature of the trapped. To describe one is to imply the other."

The culture trap, once sprung, is a merciless double bind. We cannot innovate until constraints are relaxed, but constraints will not be relaxed until an innovation has occurred. It is not just the poorest and most vulnerable members of society who close ranks in times of stress; more prosperous citizens do too. Receptiveness to new ideas is determined by how much you value what you stand to lose. Those whom the status quo has made powerful and those it has subjugated utterly cannot afford to innovate.

There are always unacknowledged human or nonhuman stakeholders in these wickedly complex problem domains (Rittell and Webber 1973). If the argument is about the best way to drain a swamp, none of the protagonists will willingly consult the frogs. When ontologies are contested, every intervention actually changes the nature of the system, and so becomes a one-shot operation with repercussions across time and space.

In wicked problem domains, we cannot assign "the system" to a recognizable category without aggravating social exclusion. There is no stable conjuncture and no prospect of generalization. The analytical approach, if we were foolish enough to try it, would almost certainly have unforeseen consequences. Simply to have someone taking notes in the corner could undermine stakeholder confidence and change the course of history. We need a discursive effort of mediation and conflict management (Vickers 1965, Boulding 1978, Flood and Jackson 1991).
This is why it is possible for a well-fed citizen to walk past a starving neighbor and see only a troublesome stranger. Even those who are moved to pity may be reluctant to deviate from cultural norms. The principal lesson of 20th-century genocide has been that, in times of co-evolutionary stress, the culture trap can be so deep that neither reason nor compassion can extricate us. Ordinary, gentle people have done the most horrible things rather than repudiate cultural markers.

\section{EMERGENCE: A KEY CONCEPT}

The word "emergence" stands on two conceptual props. The first, conventionally associated with the 19th-century philosopher George Henry Lewes, has to do with unpredictability. An event is emergent if it is not contingent, i.e., cannot be deduced from axiomatic first principles. This links it to the antireductionist thesis that the whole is not just a collection of discrete parts that can be bounded, studied in isolation, and reassembled (Holland 1998, Morowitz 2002).

The second conceptual prop, arguably the more intuitive, has to do with unfolding and spontaneous self-organization, which is sometimes called autopoiesis. Just as a rabbit emerges from a hole and a seedling from the ground, so emergent order builds itself spontaneously. A bristlecone pine tree, the solar system, and the iridescence at the interface of a puddle and an oil film are all emergent structures in this spontaneous, self-organizing sense. The word "spontaneous" tells us nothing about rates; it merely implies the absence of an external agency, as planetary orbits are emergent properties of interacting masses. The gradual corrosion of a bridge is spontaneous, for example.

The two types of emergence have different spatial, organizational, and/or temporal signatures, as illustrated by the following examples.

Both types of emergence may be manifest at different hierarchical levels in the same system at the same time. This is because of a dynamic synergy between networked subsystems. The behavior of an isolated atom, for example, is unpredictably emergent, but the orbit of the moon around the earth is a self-organizing, emergent property of the earthmoon system. The conjunctural whole is constrained by the connections between nearby atoms that somehow damp individual uncertainties out. As long as that synergetic conjuncture persists, 
we can predict the behavior of the whole using Newton's laws. The behavior of the same atoms spread out over a huge interval of space, however, would be unpredictable because breaking those connections would eliminate synergetic damping.

Hierarchical relationships between unpredictability and self-organizing emergence have led many system theorists to speculate that a well-formed hierarchical structure is a universal or at least extremely common feature of complex systems. In this respect, at least, there is a strong resonance between 20th-century hierarchy theory, taxonomy, and medieval scholasticism (Koestler 1967, Winder 2004).

Certainly, a similar hierarchical relationship is also manifest between unpredictability and constraint in the static hierarchies of biological taxonomy. If we are told that a plant is a member of the genus Papaver, we can predict that it will possess all the essential attributes of this genus of poppies. Viewed at the generic level, the specific attributes that distinguish, say, the common poppy (Papaver rhoeas) from the opium poppy (Papaver somniferum) will be unpredictably emergent. The only constraints in taxonomic hierarchies are logical, i.e., the definitions that bound the genus and its species. However, the hierarchical relationship between unpredictability and order is comparable to that found in synergetic hierarchies.

Finally, as if to refute the thesis that hierarchy is a universal property of self-organizing systems, we can sometimes find the two forms of emergence manifest on the same hierarchical level, but separated in time. The numbers that would win a future lottery, for example, are emergent in the first sense. They are unpredictable. Those numbers emerge from the machine in the second selforganizing sense. The future intergrades with the past, and uncertainty emergence gives way to selforganizing emergence. Here we are not dealing with a synergetic constraint on dynamic hierarchies or a logical constraint on static hierarchies, but with a temporal constraint on an individual object.

Temporal emergence can be slightly more subtle than the lottery example suggests. The past can also have emergent properties that self-organize in a contemporary landscape. An archaeologist cannot deduce what an excavation will reveal, for example, but, as the work proceeds, new structures emerge that may change his/her knowledge of the past. S/ he can even construct a hypothesis that can be empirically tested this way, predicting the past and testing that prediction by performing fieldwork or desk-based research using archives from earlier case studies. The time constraints that convert uncertainty emergence into self-organizing emergence are not artifacts of an objective, universal time that transforms whole landscapes. They relate to a subjective time defined relative to the individual exploring that landscape.

\section{NARRATIVE IS NOT CAUSE}

The introduction of a subjective element obliges us to consider the relationship between landscape and time. Two parallel developments are significant. Time geography is an approach that originated in Sweden in the 1950s and 1960s (Hägerstrand 1975, 1985). Time perspectivism is a theme of archaeological research that emerged in the 1980s and 1990s (van der Leeuw 1989, Winder 1993 , 1999, 2007, Murray 1999, Olivier 2001, Bailey 2007). There have, of course, been parallel developments in other disciplines, but without the emphasis on landscape that we see in these. See, for example, Faber and Proops (1993) in economics.

All the information we have about the past and the future is valorized in a contemporary landscape, either from direct observation or from memory. The two props of emergence appear antithetical, not because they have different relations to universal space-time, but because we actually organize this information in different ways to construct different space-time perspectives. Unpredictability tends to be a small-scale phenomenon or linked to future events in personal time. Predictability tends to be a large-scale phenomenon and an attribute of stable species, equivalence classes, or populations.

The "possibility space" of all lotteries, for example, is the collection of all possible lottery outcomes. It stands in relation to the lottery as a genus does to an individual species. Although the behavior of this particular lottery is unconstrained ex ante, we are confident that it will be an element of that possibility space. Possibility spaces and constraints are abstract structures. We infer them using experience, logic, and intuition, but cannot observe them directly, i.e., they do not exist out there in the landscape. However, for all this, we can develop abstract reasoning methods that represent these spaces and logical manipulations of them. The marks on paper 
created when we solve problems analytically and the patterns on a computer screen that represent the output of a computer simulation are pockets of local order (POLOs) in a landscape that we use to valorize the future or the past.

The fact that we can often build POLOs in which system behaviors become predictable can play us false if we shift space-time perspectives without realizing that we have done so. What we see when we look backward in time, for example, is not a space of possibilities, but a space of inferred events. This ex post perspective leads us to construct a narrative chain comparable to our own experience of subjective time. The events we infer from information in a contemporary landscape organize themselves into a temporal sequence like falling dominos. We tend to assume that this sequence is not abstract and subjective, but concrete and objective, and start looking for patterns. Those patterns often suggest some sort of connectedness in the event space that we naturally generalize to the future. The following text, a handwriting exercise from schooldays, illustrates the process:

For the want of a nail the shoe was lost, For the want of a shoe the horse was lost, For the want of a horse the battle was lost, For the want of the battle the kingdom was lost,

And all for the want of a horse-shoe nail.

Humans are very clever at spotting patterns in events. Skilled poker players, for example, tend to have strong memories and be good at reading body language. These faculties give them a hint about the likely constraints acting on fellow players, which they then use to make strategic guesses about risk and opportunity. An important part of the trick is to form an intuitive appreciation of the relationship between the event space, i.e., the set of inferred past events, and the possibility space of future events. It is natural to look for continuity between patterns in the remembered past and the anticipated future, but the method is far from dependable. You cannot predict the loss of a kingdom from the loss of a horseshoe, even though you may feel with hindsight that the event was pivotal.

\section{METASTABILITY AND INNOVATION}

Ludwig von Bertalanffy (1968) presented his thesis that analytical systems method could be generalized by exploring the concept of equifinality. A selforganizing structure is constrained to remain in a bounded possibility space of viable end states. A poppy seed will either germinate or not. If it does, it will grow into a poppy, not a linden tree or a frog. If it grows, it will flower or not, set seed or not. Its environment will influence its development, of course, but the possibility space that describes these systems is bounded and knowable a priori, even though the precise end state of this particular seed is uncertain.

In this, von Bertalanffy was connecting the event space to the possibility space by means of a perfectly reasonable continuity assumption, imposing a taxonomy on that event space ex post and assuming continuity of experience ex ante. The method works rather well, as one can verify by planting a packet of poppy seeds.

According to von Bertalanffy, the principle of equifinality can be generalized to ecological and social "organisms," but his thesis raises a fundamental theoretical question. If the possibility space explored by a complex adaptive system is static and classifiable, are we justified in claiming that the whole is more than the sum of its parts? The question of hyperdeterminism can be set aside. We have known for 80 years that we cannot deduce a poppy from Newton's laws. However, if we get the taxonomy right, we have the strong impression that deducibility is locally possible. You can look at the seed through a microscope and assign it to the species Papaver rhoeas. From that diagnosis you can deduce that the seed, if it germinates, will grow into a poppy plant. Even though we cannot deduce that the individual seed will germinate, we can speak of the probability that a seed, selected at random from a packet of similar seeds, will germinate. A packet of poppy seeds, then, suggests a metastable system, and we can use analytical method to make statistically robust predictions.

In practice, of course, the destruction of predictive uncertainty through time sometimes results in an elaboration of structure. This is what some 19thcentury scientists referred to as "evolution" (Huxley 1870, Spencer 1937) or "descent with modification" (Darwin 1859). Elaboration is conventional autopoiesis with an element of surprise. Instead of 
getting a new instance of a familiar species, the possibility space is augmented in some way as new species come into being. Modern urban societies are larger and more highly differentiated and stratified than hunter-gatherer societies, and this structure has emerged over time.

For many analytical scientists, elaboration is just an interesting type of metastability. The possibility space is fixed and time invariant. Although new species may emerge, they were always there in the sense that there were regions of the possibility space, i.e., attractors or Platonic forms, that corresponded to those species. The new species emerged when those attractors were finally colonized. Prigogine (1978) has championed this formalist model, speaking of perturbations that drive a system far from equilibrium and lead to spontaneous reorganization and elaboration of structure (see also Haken 1978).

Elaborative metastable systems are thermodynamically open, i.e., capable of receiving information and material such as perturbations from outside, but logically closed. The attractors corresponding to species and genera are formally real and time invariant. If the whole is more than the sum of its parts, it is so trivially because one of the parts, although always there, has not yet been discovered. The fact that elaborative systems can sometimes surprise us is merely a function of our imperfect understanding. If those Pleistocene huntergatherers had not been working with incomplete information, they could have foreseen the possibility of a deeply stratified imperial structure. We, who have the benefit of a more advanced science, can see this clearly.

Logical closure is a constraint that ensures that the system at hand is computably complex. It is broadly equivalent to the assumption that scientists stand outside the system they are studying. However, discursive scientists, those who study socio-natural systems, are actually part of the systems they study. Their knowledge influences behavior and behavior, in turn, modifies the system, which feeds back into the epistemic domain, changing conceptual taxonomies. This is not just so of human knowledge. Any creature capable of developing a conditioned reflex and learning new responses to a familiar situation is in this position.

Thus, our ability to anticipate and take preemptive action can change the course of history in a completely unpredictable way (Popper 1959). Once we get past the end of the current conjuncture, the "system" may no longer exist, because the boundary judgments that define it and the constraints that sustain it are by-products of habit and structured behavior. We cannot anticipate categories of which we currently have no knowledge (Popper 1982). This is variously called "uncomputable complexity," "logical unconnectedness" (Chaitin 1982, Rosen 2000), or "logical openness." Ex ante, unpredictable elaboration of this sort is here called "innovation."

\section{THREE TIME PERSPECTIVES}

Annales historians distinguish three time perspectives (Braudel 1980; see Liljenström and Svedin 2005, Chapter 1, for an independent model). Deep time (the longue durée) is so slow as to be almost static. Conjunctural time (conjoncture) is the median time of economic, political, cultural, and biological processes. This is the scale on which connectedness creates synergetic constraints that make prediction possible. Event time (histoire événementielle) is the time frame of "small history," current affairs, and daily life. Viewed against the backdrop of deep time, conjunctures often appear as more or less predictable cycles. Examples include the punctuated equilibria of evolutionary systems (Gould 1980), the boom/bust cycles of economic growth, Phoenix Cycles of war and peace, the cyclical sociologies of Karl Marx and Herbert Spencer, the Lotka-Volterra cycles of animal populations, or the nested adaptive cycles of panarchy theory.

Let us define a causal relationship in terms of a process that forms a logical connection between the state of a conjuncture at some time in the past and its current state. That logical connection can be deductive or probabilistic. It is therefore reasonable to say that a storm was caused by an occluded front, but absurd to suggest that it was caused by a butterfly. There is no logical connection, not even on the balance of probabilities, between the event that was a butterfly flapping its wings and the weather now.

Beneath the conjunctural level we see the small history of events. Events are anti-causal objects, logically unconnected to the past in the arena at hand, although they may form an interpretable narrative sequence. However, events are capable of stimulating an epiphany, i.e., a change of perception 
that actually transforms the system's causal structure.

Epiphanies are the little "Aha!" moments when individuals deviate from routine and habit and the system reorganizes itself at the conjunctural level. New behaviors are likely to have unfamiliar structures that, if not damped out by synergetic connectedness, may spread contagiously and modify processes at the conjunctural level. This is an innovation. Under certain circumstances, chain reactions of epiphanies can trigger an innovation cascade that appears in the historical record as a revolutionary change. Many innovation cascades follow in the wake of co-evolutionary catastrophes that eliminate or suspend the synergetic veto.

As we look backwards, we see successive conjunctures and events set against the backdrop of deep time. A causal process transforms states to define the conjunctural scenery against which the narrative of small history is played out. From time to time, pivotal events occur that, with the wisdom of hindsight, seem to have presaged a conjunctural shift. These epiphanies move the system from one conjuncture to another.

Causal and anti-causal structures always have different time-space signatures in the synergetic hierarchy at hand. Processes are the causal upshot of synergetic constraints; they limit microlevel behavior from the top down, making it possible to predict future states within the conjuncture at hand. Epiphanies, even those initiated by massive exogenous or co-evolutionary catastrophes, become manifest in the system on a microscale and, if they are not smothered by synergetic constraint, reorganize system dynamics anti-causally, from the bottom up.

We are all familiar with the ex ante uncertainty experienced when looking forward. Although we can extrapolate the causal simplicity of the conjuncture and sometimes even predict the synergetic bottleneck that may precipitate a coevolutionary catastrophe, we naturally tend to think on a human scale. The longue durée is easily neglected, and we get lost in the small history of daily business and "What if?" questions.

It is almost impossible to distinguish the anti-causal event that will change the course of history from events that will simply divert us for a while and be forgotten. As time passes, event crowds on anti- causal event, but we do not actually know how things will turn out. We realize that an event was pivotal only from a vantage point in the future. As Søren Kierkegaard put it: We live our lives forward, but make sense of them backwards. This imposes a limit on predictability that not only makes the future uncertain (Prigogine 1996), but may also make current ideas about possibility spaces meaningless.

\section{PREDICTION AND JONAH'S LAW}

All taxonomies are logically open, although some are more robust than others. We can predict the mean summer temperature on the top of Ben Nevis in the year 2500, for example, because the taxonomy of mountains and temperatures is ontologically robust in this arena. The prediction may not be very useful, of course, but at least it is meaningful. Predicting the gross domestic product of Scotland in 2500, however, would imply that the polity and its economy would still be recognizable 500 years from now. Such a prediction is not just operationally useless; it is meaningless.

To make predictions that can be tested empirically, we have to be confident that our taxonomies will not change in the arena at hand. In practice, this often means that the system must be highly constrained, i.e., it must be either a natural system that cannot be modified by human agency or an extremely brittle socio-natural system in which any attempt to innovate would precipitate a collapse. We can sometimes make testable predictions with regard to systems with more adaptive potential, but only by being secretive. If we share our hypothesis with people inside the system, they may innovate preemptively and spoil the experiment.

Such dispassionate experiments are often ethically indefensible. A model that predicts a catastrophic cascade of collapsing life-support systems cannot just be logged in an obscure journal for future reference. We have to innovate in response to this perceived threat. If we are successful, we will have changed the course of history in a way that makes old boundary judgments obsolete.

Cultural ecodynamics are therefore governed by Jonah's law. We can only predict the course of history in systems whose behavior we cannot influence. We can only change the course of history if the system has enough wiggle room to ensure that our predictions are not only uncertain, but also quite 
possibly meaningless. This is because every prediction carries a hidden contingency: $\mathrm{X}$ will happen if you don't innovate to stop it from happening.

Neither the positivist thesis that experimental results can verify hypotheses nor the rationalist antithesis that scientific hypotheses can only be falsified have much bearing in cultural ecodynamics. It is a matter of personal and political preference whether one takes a hard line, declaring cultural ecodynamics to be a nonscience, or whether one shifts the boundaries of science to accommodate uncomputable complexity. To exclude it, however, one must also exclude ecology, evolution, 20th-century mathematics, economics, and sociology, which would produce the sort of science curriculum imposed on schools in Tennessee between the two world wars.

\section{CONCLUSIONS}

There were actually two complexity revolutions in the 20th century. The first revolution began between the wars, when analytical scientists finally accepted that hyperdeterminist theories were untenable, that the whole was more than the sum of its parts, and that we could not deduce a poppy from Newton's laws even in theory. The boundaries of analytical science gradually widened to accommodate computable complexity and metastable dynamics.

The success of wartime "Big Science" left systems researchers sending out conflicting signals during the Cold War. On the one hand, we had the politically astute, who argued that space-age science would soon be so advanced that poverty would disappear. Most repetitive work and a great deal of technical problem solving would be delegated to machines, and we would need a new type of education to prepare us for this affluent society. On the other hand, we had practitioners who understood that problems of social exclusion could not be solved analytically, although they could sometimes be tackled discursively.

The generality of chaotic and nonlinear systems method was still being overstated through the 1980s and 1990s. For humanists and softer practitioners, this "physics envy" was almost embarrassing because it suggested that the systems community had failed to grasp the distinction between thermodynamic openness and logical openness. Although it is possible to build mathematical models to imitate the unpredictability of socionatural systems, these are either pedagogic "toyworld" models or are used to solve logically closed problems like routing telephone calls or characterizing the attractors of chemical systems.

Simulation models have little direct impact on migration behavior, so the method can sometimes be generalized to ex ante studies in demography or population ecology. However, in anthropology and sociology, dynamic models are usually restricted to ex post case studies in which logical closure can be assumed. Generalizing from ex post computable complexity to ex ante uncomputable domains is seldom justified, but the political demand for infrastructural solutions to uncomputably complex problems would brook no opposition. By the late 1980s, the post-modern standoff had driven a wedge between the analytical and discursive sciences that frustrated their integration into the academic mainstream.

The work continued in applied and policy-relevant settings. The success of this journal is a measure of that commitment. By the end of the 20th century, the boundaries of science had widened again, this time to accommodate uncomputable complexity and innovative dynamics. Jonah's law now governed our predictions. The cost of this is that many analytical predictions are now known to be meaningless, but the potential benefit greatly outweighs that cost. We know more about socionatural systems than ever before. What we have learned over the past few decades means that, instead of being satisfied merely to predict, we can now help break the Phoenix Cycle by facilitating innovation.

Issues of receptivity are clearly significant. The material constraints that made urban life unattractive to hunter-gatherers also prevent advanced societies from living more simply today. A tired commuter on the train would not swap places with a peasant who labored from dawn to dusk for bread, cheese, and homespun clothes. Few of us would want our children to work in airless factories or tolerate the floggings and executions needed to keep people in order. This option is not part of our current possibility space. Of course, a coevolutionary catastrophe could change all that. As Holling (2001) wisely explains, the term "sustainable development" is no oxymoron; it is the only alternative to the Doomsday Scenario. 
We will see in the Appendix to this paper that the most primitive urban societies were those that emancipated one social stratum by enslaving another. Through successive Phoenix Cycles, some were able to mitigate these stresses, building infrastructure to emancipate the core by enslaving the periphery. As communications technology improved, core and periphery have become increasingly remote. Today, Malthusian stress is virtually unknown within advanced technocracies. Unacknowledged stakeholders in the Third World and remote nonhuman species now pay the price of our prosperity.

It is doubtful that this strategy will still be sustainable when the older superpowers finally become integrated with the new superpowers of the Far East. It might seem natural to call for draconian legislation to force us all to behave more responsibly. However, clumsy intervention would spring the culture trap, aggravating social exclusion among the most vulnerable and driving the powerful into their cultural laagers. This would reduce the amount of adaptive wiggle room and frustrate innovation.

There is no obvious technological solution to the problems of globalization. The best we can do is to extend the conceptual structures of system theory in ways that help us understand, discuss, and manage systemic change. Intergenerational equity is important, of course, but co-evolutionary catastrophes have deepened alarmingly over the last three centuries. If we cannot soon locate more resilient configurations, there may not be many more generations to share resources with. The model presented here suggests that it may not be necessary for wealth to be spread evenly across the planet or between species and generations. However, a fairer distribution of adaptive potential is imperative.

Responses to this article can be read online at: http://www.ecologyandsociety.org/vol12/iss2/art28/responses/

\section{Acknowledgments:}

This is the positioning statement of Workpackage 4 of ISBP (Integrative Systems and the Boundary Problem) funded under the 6th Framework Programme of the EU (project number 043199). It was drafted in close consultation with Claudia
Dürrwächter, Veronica Hernandez-Jimenez and Kim Seaton, all of whom have case-study reports in prep. I am especially grateful to Geoff Bailey, the late Torsten Hägerstrand, and Sander van der Leeuw for encouraging me to think more carefully about space, time, material objects, and innovation. I also thank Heather Winder, Dwight Read, and Hans Liljenström for comments on an earlier draft.

\section{LITERATURE CITED}

Allen, T. F. H., and T. D. Starr. 1987. Hierarchy: perspectives for ecological complexity. University of Chicago Press, Chicago, Illinois, USA.

Bailey, G. 2007. Time perspectives, palimpsests and the archaeology of time. Journal of Anthropological Archeology 26: 198-223.

Bhagwati, J. 1966. The economics of underdeveloped countries. Weidenfeld and Nicolson, London, UK.

Binford, L. R. 1983. In pursuit of the past: decoding the archaeological record. Thames \& Hudson, London, UK.

Boulding, K. 1956. General system theory: the skeleton of science. Management Science $\mathbf{2}$ (3):197-208.

Boulding, K. 1978. Ecodynamics: a new theory of societal evolution. Sage, London, UK.

Braudel, F. 1980. On history. University of Chicago Press, Chicago, Illinois, USA.

Brundtland, G., editor. 1987. Our common future: the World Commission on Environment and Development. Oxford University Press, Oxford, UK.

Carson, R. 1962. Silent spring. Houghton Mifflin, New York, New York, USA.

Chaitin, G. J. 1982. Gödel's theorem and information. International Journal of Theoretical Physics. 22:941-954.

Churchman, C. W. 1979. The systems approach. Second revised edition. Delacorte Press, New York, New York, USA. 
Darwin, C. 1859. On the origin of species by natural selection. Murray, London, UK.

Faber, M., and J. R. Proops. 1993 Evolution, time, production and the environment. Springer-Verlag, Berlin, Germany.

Flood, R. L., and M. C. Jackson, editors. 1991. Critical systems thinking: directed readings. Wiley, Chichester, UK.

Folke, C. 2003. Social-ecological resilience and behavioural responses. Pages 226-242 in A. Biel, B. Hansson, and M. Mårtensson, editors. Individual and structural determinants of environmental practice. Ashgate, Aldershot, UK.

Gell-Mann, M. 1994. The quark and the jaguar: adventures in the simple and the complex. Freeman, New York, New York, USA.

Gould, S. J. 1980. Is a new and general theory of evolution emerging? Paleobiology 6(1):119-130.

Gunderson, L. H., and C. S. Holling, editors. 2001. Panarchy: understanding transformations in human and natural systems. Island Press, Washington, D.C., USA.

Hägerstrand, T. 1975. Survival and arena: on the life-histories of individuals in relation to their geographical environment. Monadnock 49:9-29.

Hägerstrand, T. 1985. Time geography: focus on the corporeality of man, society and environment. Pages 193-216 in S. Aida, editor. The science and praxis of complexity. United Nations University, New York, New York, USA.

Hägerstrand, T. 1987. Om tidens vidd och tingens ordning —några synpunkter på innovationsförloppets historiska geografi. Geografi i Bergen 108:14-22.

Haken, H. 1978. Synergetics: an introduction. Springer-Verlag, Berlin, Germany.

Holland, J. 1998. Emergence: from chaos to order. Oxford University Press, Oxford, UK.

Holling, C. S. 1973. Resilience and stability of ecological systems. Annual Review of Ecology and Systematics 4:1-23.

Holling, C. S. 2001. Understanding the complexity of economic, ecological and social systems. Ecosystems 4:390-445.

Huffaker, C. 1958. Experimental studies on predation: dispersion factors and predator-prey oscillations. Hilgardia 27:343-383.

Huxley, T. H. 1870. Palaeontology and the doctrine of evolution. Page 305 in Discourses biological and geological, presidential address to the Geological Society. Appleton, New York, New York, USA.

Koestler, A. 1967. The ghost in the machine. Hutchinson, London, UK.

Lakof, G., and R. E. Núñez. 2000. Where mathematics comes from: how the embodied mind brings mathematics into being. Basic Books, New York, New York, USA.

Lee, K. 1993. Compass and gyroscope: integrating science and politics for the environment. Island Press, Washington, D.C., USA.

Liljenström, H., and U. Svedin. editors. 2005. Micro-meso-macro: addressing complex system couplings. World Scientific, Singapore.

Lovelock, J. 1979. Gaia: a new look at life on Earth. Oxford University Press, Oxford, UK.

Morowitz, H. J. 2002. The emergence of everything: how the world became complex. Oxford University Press, Oxford, UK.

Murray, T., editor. 1999. Time and archaeology. One World Archaeology, London, UK.

Naess, A. 1989. Ecology, community and lifestyle: outline of an ecosophy. Cambridge University Press, Cambridge, UK.

Norgaard, R. B. 2005. Bubbles in a back eddy: a commentary on "The origin, diagnostic attributes and practical application of coevolutionary theory." Ecological Economics 54:362-365.

Olivier, L. 2001. Temps de l'histoire et temporalités des matériaux archéologiques : à propos de la nature chronologique des vestiges matériels. Antiquités Nationale 33:189-201.

Poincaré, H. 1952. Science and method. Dover, New York, New York, USA. 
Popper, K. 1959. The logic of scientific discovery. Hutchinson, London, UK.

Popper, K. 1982. The open universe: an argument for indeterminism. Hutchinson, London, UK.

Prigogine, I. 1978. Time, structure and fluctuations. Science 201:777-785.

Prigogine, I. 1996. The end of certainty: time, chaos and the new laws of nature. Free Press, New York, New York, USA.

Read, D. W. 2003. From behavior to culture: an assessment of cultural evolution and a new synthesis. Complexity 8(6):17-41.

Renfrew, A. C. 1979. Problems in European prehistory. Edinburgh University Press, Edinburgh, UK.

Rittel, H. W. J., and M. M. Webber. 1973. Dilemmas in a general theory of planning. Policy Studies 4:155-169.

Rosen, R. 2000. Essays on life itself. Columbia University Press, New York, New York, USA.

Rosenhead, J., and J. Mingers. 2001. Rational analysis for a problematic world revisited: problem structuring methods for complexity, uncertainty and conflict. Wiley, New York, New York, USA.

Russell, B. 1961 History of western philosophy and its connection with political and social circumstances from the earliest times to the present day. Second edition. Routledge, London, UK.

Sahlins, M. 1972. Stone Age economics. Tavistock, London, UK.

Schumacher, E. F. 1973. Small is beautiful: a study of economics as if people mattered. Bond and Briggs, London, UK.

Schumpeter, J. A. 1939. Business cycles: a theoretical, historical and political analysis of the capitalist process. McGraw-Hill, London, UK.

Slobodkin, L. B. 1961. Growth and regulation of animal populations. Holt, Reinhart and Winston, New York, New York, USA.

Spencer, H. 1885. Principles of sociology. Volume
I. Revised edition. Williams \& Norgate, London, UK.

Spencer, H. 1937. First principles. Sixth edition. Watts, London, UK.

Urry, J. 2003. Global complexity. Polity Press, Cambridge, UK.

Van der Leeuw, S. E. 1989. Risk, perception, innovation. Pages 300-329 in S. E. van der Leeuw and R. Torrence, editors. What's new? A closer look at the process of innovation. One World Archaeology, Unwin Hyman, London, UK.

Van der Leeuw, S. E. 1998. Understanding the natural and anthropogenic causes of land degradation and desertification in the Mediterranean Basin: the Archaeomedes Project. Office for Official Publications of the European Communities, Luxembourg.

Vickers, G. 1965. The art of judgment: a study of policy making. Chapman and Hall, London, UK.

Vickers, G. 1972. Freedom in a rocking boat. Pelican, London, UK.

Volterra V. 1926. Variations and fluctuations in the number of individuals in animal species living together. Pages 409-448 in R. N. Chapman, editor. Animal ecology. McGraw-Hill, New York, New York, USA.

von Bertalanffy, L. 1968. General system theory: foundations, development, applications. George Braziller, New York, New York, USA.

Watt, A. 1947. Pattern and process in the plant community. Journal of Ecology 35:1-22.

Winder, N. 1993. Using modern bone assemblages to estimate ancient populations. Circea $\mathbf{1 0}$ (2):63-68.

Winder, N. 1997. Dynamic modelling of an extinct ecosystem: refugia, resilience and the overkill hypothesis in Palaeolithic Epirus. Pages 615-636 in G. N. Bailey, editor. Klithi: palaeolithic settlement and quaternary environments in northwest Greece. Volume 2. Klithi in its local and regional setting. McDonald Institute for Archaeological Research, Cambridge, UK. 
Winder, N. 1999. The historian's dilemma, or Jonah and the flatworm. Human Ecology Review 6 (2):23-31.

Winder, N. 2004. Towards a theory of knowledge systems for integrative socio-natural science. Human Ecology Review 11(2): 118-132.

Winder, N. 2005. Integrative research as appreciative system. Systems Research and Behavioral Science 22:299-309.

Winder, N., editor. 2006. TiGrESS Final Report: June 2006. Available online at: http://www.tigress. ac/reports/TiGrESS final.pdf.

Winder, N. 2007. A multi-dimensional approach to the animal bone data. In C. Renfrew, N. J. Brodie, C. M. Morris, and C. J. Scarre, editors. Excavations at Phylakopi in Melos 1974-7. British School at Athens, London, UK, in press.

Winder, N., B. McIntosh, and P. Jeffrey. 2005.

The origin, diagnostic attributes and practical application of co-evolutionary theory. Ecological Economics 54:347-361. 


\section{APPENDIX 1. AN ILLUSTRATIVE EXAMPLE: SOCIAL COMPLEXIFICATION IN EUROPE}

Morowitz (2002) uses the origin of agriculture as an example of emergence. He argues that, if one considers the possibility space of human-environment interaction, agriculture is clearly an attractor, i.e., a conjuncture or genus of conjunctures, that has been colonized several times. If the tape were played again, the result would probably be agriculture.

It is perhaps pedantic to observe that the domestication of animals and plants occurred much more often than he suggests. The instances that have come to popular attention did so because domesticates were moved beyond their endemic range by people who left qualitatively new types of trace in the landscape. It is probable that animals were domesticated in the Pleistocene, for example. Plants and animals have certainly been husbanded far beyond the cradles of civilization, but there was no explosive complexification to draw attention.

More than $99 \%$ of human history has been nonurban, with very little technological specialization, no spectacular pockets of local order (POLOs) such as great buildings, and no evidence of conspicuous wealth, writing, or social stratification. Village-based agricultural societies and hunter-gatherers have different types of technology, but there is little to distinguish them in terms of social complexity. Villages are a little larger and more visible than hunting camps, but pastoralists often leave almost no trace in the landscape. Compared to the Upper Paleolithic art sites of southern France, the subsistence agriculture of prehistoric Europe and sub-Saharan Africa seems bland and unstructured. The really interesting topic, as Morowitz' book amply demonstrates, is not agriculture, but the complexification with which it is sometimes associated.

Sir Herbert Spencer believed that primitive humans were solitary, asocial beasts. Competition for limited resources brought Malthusian stress that created a natural selection pressure. This selection forced us to compete with each other, leading to conflict and war. More civilized populations that could aggregate in ever larger, more co-operative units were better able to win wars. According to Spencer (1985), "...this formation of larger societies by the union of smaller ones in war, and this destruction or absorption of smaller ununited societies by the united, larger ones, is an inevitable process through which the varieties of men most adapted for social life supplant the less adapted varieties."

One of the most striking features of Spencer's model is that the synergetic constraints restricting adaptive potential are inexorable and universal. Evolution becomes a deterministic process that drives "progress," turning apes into savages and savages into gentlemen. This progressive model remains an important structuring principle in contemporary society, especially in advanced technocracies. Whenever a science fiction story portrays a being that spontaneously "evolves" into a higher life-form, we see Spencer's cultural legacy.

Discursive scientists are reluctant to give Spencer's theory serious attention because it came to be associated with the laissez-faire economics of the empires of the late 19th century and the genocidal policies of the Third Reich. In this respect, physics is a more generous science than sociology. Physicists do not repudiate Einstein because he was wrong about physical determinism or because his work made it possible to develop atomic weapons. They retain those elements of his work that remain useful and add new ones of their own.

Spencer's hypothesis was not ridiculous. He could have known very little about the biology of great apes. Malthusian stress was then a universal feature of urban life and, indeed, of life in the rural hinterland that supplied urban markets. The best reason for rejecting Spencer's model is that it cannot be reconciled to evidence gathered after Spencer's death. Ethnographic research suggests that huntergatherers are much more predisposed to share goods and resources than urbanites are. Population 
pressure can be reduced by sanctioning alternative routes to sexual fulfillment and by practicing celibacy, infanticide, and other birth control methods.

There are very good material reasons why hunter-gatherers should avoid urban life. Sahlins (1972) described hunter-gatherers as the "original affluent society" because they were able to produce most of their subsistence needs in about $4 \mathrm{hr}$ a day. Producing enough to meet domestic needs using agriculture increases that workload, but the burden of supporting a primitive urban society is almost unbearable. Intensive mixed agriculture triples that workload, creates malnutrition, and aggravates infant and obstetric mortality rates. The urban revolutions also brought slavery and engaged the Malthusian ratchet. These were not developments that seemed like a good idea at the time. It probably took a major coevolutionary catastrophe to drive humans out of stable, extensive conjunctures into an urban configuration (Binford 1983, Chapter 8).

The simplest way to salvage Spencer's theory is to allow that it is not universally but only locally true. We divide the possibility space into two attractors. One is demographically extensive, with no or only weak Malthusian stress; the other is demographically intensive with severe Malthusian stress. The analogy with physics is rather clear: The extensive attractor is like a cloud of unconnected atoms floating in the void, whereas the intensive attractor is like a highly connected mass whose behavior is made predictable by synergetic constraints.

This small adjustment gives us a model in which socio-natural dynamics are metastable. We invoke a pivotal event or perturbation that flips the system from a demographically extensive attractor to a demographically intensive one. People must have been driven into these aggregations by the need for patchily distributed resources in times of environmental stress. In some regions it may have been stands of wild cereals; in others it could have been water for irrigation.

Once the transition was made, Spencer's model would apply without loss of generality, although his belief that sociability was the product of the Malthusian ratchet can no longer be sustained. Humans, like all the other great ape species, are innately sociable. Where hunter-gatherers tend to share subsistence resources and villages compete with other villages, we would now see people competing with their immediate neighbors. Rapid reproduction rates and co-evolutionary stress would put ruthless delinquents at a small selective advantage. Spencer's argument is turned on its head; cities actually made people less sociable.

Population growth would have made the process irreversible. The people living around the conurbation would have had strong incentives to discourage an influx of hungry refugees from the city. Trade between the centre and periphery would be favored. But what do you trade for subsistence goods when you live in a city made of mud bricks and stones? The answer seems to be that the city forms an army to protect the fields and raises taxes to pay for it. It builds infrastructure, such as irrigation systems and roads, to raise productivity. It trains people to bake clay and make pretty pots and to melt stone and make pretty metals, and then persuades its neighbors that these goods and services are intrinsically desirable. The amazing human capacity to negotiate nonadaptive cultural norms comes into its own, as they persuade each other that this is "normal." These geegaws become so valuable that farming communities give their food away to possess them.

Competition within the cities would have driven social stratification. Systems of laws would be developed to keep the peace. Slavery and capital punishment would become normal. As the population grew, the size of the exploited hinterland would grow too. Small trading posts would be established on the periphery to channel food to the centre and craft goods to the hinterland. The urban elites would need to control subsistence resources, and this would require a system of accounting and a way of managing the production of the high-status goods that brought those resources in. Markets would be established and craft specialists recruited to meet this demand. The cities would fill up with craftsmen working for the elites who would feed them with some of the food they brought in. The civilization would begin to expand, driven by the Malthusian ratchet. 
Making Spencer's model metastable is an undoubted improvement. We no longer have to look for the cause of complexification. All that is required is a co-evolutionary perturbation that drives people into a conurbation and holds them there long enough for the ratchet to engage. There were probably different perturbations in different arenas. Some of these complex societies simply collapsed, and the survivors went back to subsistence agriculture or, in some cases, to hunting and gathering. Others had access to the right combination of resources and became self-sustaining.

However, there are problems with the metastable model too. Basically, it gives us only two routes to complexification: spontaneous aggregation or trade and acculturation. In a world without good communications, this would suggest a contagious model. There is ample evidence of contagious development, but the diffusion process was remarkably slow. Urbanization crawled out of the Middle East and crept across Europe like a slow cancer. It reached southeastern Europe in the Bronze Age (about 5000 years ago) and the northwest Atlantic fringe in the Iron Age (about 2000 years ago), but it only engulfed Scandinavia in the 17th century. For metastability to be a complete model, there should be very little complexification beyond the reach of these burgeoning civilizations.

In fact, agriculture spread far beyond the cradle of civilization and may indeed have been discovered independently in many regions. However, extreme Malthusian stress and runaway complexification did not spread with it. The first Middle Eastern civilizations had bronze-working and advanced pottery technology, so European archaeologists tended to see the pyrotechnologies as the fingerprint of urbanization. However, in the 1960s and 1970s, they discovered that pyrotechnology, like agriculture, spread much faster than urbanization.

The Bronze Age settlements of Crete do indeed look a little like urban units, but those of nearby Mycenae look more like fortified villages with warrior elites. No doubt there were famines and infant and obstetric mortality, but nothing like those experienced by Middle Eastern cities, where densitydependent diseases would have claimed many. It is conceivable that Mycenae was a second-order contagious development from the Middle East, but what about the Bronze Age societies on the Atlantic Fringe?

The later Neolithic and Bronze Age communities of these regions produced some beautiful artifacts and impressive POLOs, including rich burials, stone circles, and megalithic structures, that naturally make people think of social complexification. However, there is no evidence here of demographic runaway or, indeed, of any sort of physical crowding. This is not a spontaneous aggregation event. Neither is there much likelihood of contagious development through contact with the Middle East because these sites are rather early, possibly even older than the Mycenaean (Renfrew 1979).

There was little transport infrastructure to facilitate contact between Britain and the Mediterranean before the second century BC. Exchanges of material goods would have been possible over such distances, but could hardly have been intensive enough to aggravate Malthusian stress on the western fringe. We have no reason to believe that the Bronze Age communities around Stonehenge would ever have developed into an urban civilization spontaneously. This is a different type of complexification, one in which most competition is directed between neighboring communities rather than between neighbors in the same settlement.

Metastable models based on the Spencerian mechanism do not explain complexification of this sort or, indeed, the incipient complexification of the European Palaeolithic. However, they capture the core dynamics of urban systems quite well, at least until the 20th century, when we start seeing cities with virtually no Malthusian stress. We therefore need to generalize them in a way that accommodates the dynamics of less severely constrained systems. Building innovation into the model does this nicely. We admit the possibility that the level of synergetic constraint can vary. System behavior is predictable and organized within conjunctures, and more chaotic and unpredictable when constraints are relaxed and adaptive potential is released. 
The intensity of those synergetic constraints is often linked to demographic and other co-evolutionary pressures. If food is scarce or the demand for resources high, societies end up playing a "zero-sum game" in which each person's gain is another's loss. Structured behaviors become cultural markers and constraints harden, initiating a Phoenix Cycle of entrenchment and collapse. After collapse, adaptive potential is freed up, and people can develop mitigating strategies that reduce conflict, conserve those aspects of old life ways they value, and abandon those they do not. The interaction of memory with anticipation and aspiration gives historical systems their ex post path dependence, which makes narrative possible, but also provides enough adaptive wiggle room to make them unpredictable ex ante.

The history that actually happened represents only one of many possible pathways, and any model that "predicts" that trajectory to the exclusion of others can usually be dismissed on a priori theoretical grounds. Historical systems are potentially innovative, and their behavior is uncomputably complex. They only become metastable, i.e.,computably complex, when synergetic constraints are unremitting and adaptive potential is curtailed. 